\title{
Problem gambling among Czech adolescents: An exploration of its relationship to early initiation of tobacco smoking
}

\author{
MARTIN ŠPOLC ${ }^{1}$, VIKTOR MRAVČÍK ${ }^{2,3,4}$, BARBORA DRBOHLAVOVÁ ${ }^{3,4}$ and PAVLA CHOMYNOVÁ ${ }^{4}$ \\ ${ }^{1}$ Institute of Economic Studies, Faculty of Social Sciences, Charles University in Prague, Prague, Czech Republic \\ ${ }^{2}$ National Monitoring Centre for Drugs and Addiction, Office of the Government of the Czech Republic, Prague, Czech Republic \\ ${ }^{3}$ Epidemiological and Clinical Research of Addictions, National Institute of Mental Health, Klecany, Czech Republic \\ ${ }^{4}$ Department of Addictology, First Faculty of Medicine, Charles University and General University Hospital in Prague, \\ Prague, Czech Republic
}

(Received: May 22, 2018; revised manuscript received: November 27, 2018; accepted: December 24, 2018)

\begin{abstract}
Background and aims: Gambling in adolescence is often related to licit and illicit substance use. Some evidence shows that teenage smokers gamble more than non-smokers. The aim of the study is to analyze the relationship between problem gambling and smoking among Czech adolescents. Methods: Data on 6,082 adolescents (50.1\% boys and $49.9 \%$ girls) aged $15-19$ years were collected as part of the ESPAD study in the Czech Republic in 2015. Logistic regression and linear regression models were used to test the hypothesis that the early onset of daily smoking increases the risk of problem gambling. Results: The age of initiation of daily smoking seems to be a more reliable marker of the risk of problem gambling than smoking status or intensity of smoking. More than $20 \%$ of smokers who started smoking daily at the age of 12 years or earlier are at risk of problem gambling, which shows a significantly increased probability compared to non-smokers $(\mathrm{OR}=2.7)$. Other factors that increase the chances of becoming a problem gambler include being male, of higher age, and a student of a secondary school. Discussion and conclusions: The relationship between adolescent smoking and gambling is complex and is likely to be influenced by other underlying factors. Early daily smokers and at-risk gamblers tend in a similar way to risky behavior as a result of impulsivity. Interventions targeting early smoking and other substance-use behavior should not only aim at quitting smoking but could also include preventing smokers from developing problem gambling.
\end{abstract}

Keywords: adolescents, gambling, problem gambling, smoking, early initiation, ESPAD

\section{INTRODUCTION}

The increased availability of gambling as a result of widespread access to the Internet and the high level of adolescents' participation in gambling in developed countries are raising the importance of adolescent gambling as a public health issue (Volberg, Gupta, Griffiths, Olason, \& Delfabbro, 2010). A recent review of worldwide research showed a high prevalence of both participation in gambling (Delfabbro, King, \& Derevensky, 2016) and problem gambling (Calado, Alexandre, \& Griffiths, 2017) in some European countries, suggesting that a substantial proportion of Czech adolescents might also be engaged in gambling activities. Data from the latest wave of the ESPAD study carried out in 2015 showed that $9 \%$ of 16-year-old Czech adolescents reported having gambled for money in the past 12 months $(15 \%$ of the boys and $3 \%$ of the girls; Chomynová, Csémy, \& Mravčík, 2016), or up to $18 \%$ if both online and offline gambling activities are considered (Molinaro et al., 2018). In the European context, the Czech Republic, together with Malta, Austria, Netherlands, Ukraine, Norway, Sweden, Liechtenstein, Lithuania, and
Iceland, is one of the countries with a low prevalence of gambling (Molinaro et al., 2018).

Adolescents are more vulnerable to risky behaviors such as gambling than adults (Derevensky, Gupta, \& Winters, 2003). Although adolescents should have limited access to gambling activities, a majority of adolescents have gambled for money at least once in their lifetime (Delfabbro et al., 2016). Although most adolescents who have gambled do not subsequently suffer from severe problems, some are at risk of developing a gambling disorder. Involvement in problem gambling in adolescence increases the severity of gamblingrelated problems in young adulthood, including indebtedness, psychosocial impacts, and suicidal behavior (Richard, Blaszczynski, \& Nower, 2014). From the point of view of public health policy, identifying the predictors of adolescent

\footnotetext{
* Corresponding author: Pavla Chomynová; National Monitoring Centre for Drugs and Addiction, Office of the Government of the Czech Republic, Nabrezi E. Benese 4, Prague 1, CZ-11801, Czech Republic; Phone: +420 224003 822; E-mail: chomynova.pavla@ vlada.cz
}

This is an open-access article distributed under the terms of the Creative Commons Attribution-NonCommercial 4.0 International License, which permits unrestricted use, distribution, and reproduction in any medium for non-commercial purposes, provided the original author and source are credited, a link to the CC License is provided, and changes - if any - are indicated. 
problem gambling may be of great importance for prevention and early intervention programs.

Smoking, and especially daily smoking, is one of the most widespread forms of substance use among adolescents, representing a serious public health concern in itself, also because the majority of adult smokers started smoking in adolescence (United States Department of Health and Human Services, 2014). A positive correlation between problem gambling and smoking has been established in the literature both in adults (Hayatbakhsh, Clavarino, Williams, Bor, \& Najman, 2012) and adolescents (Kong et al., 2013; Molinaro et al., 2018; Volberg et al., 2010; Weinberger et al., 2015a, 2015b).

Analyzing the relationship between adolescent gambling and smoking in a sample of Connecticut secondary school students, Weinberger et al. (2015b) showed evidence that smokers gambled more severely than non-smokers. A second study based on the same sample found out that gamblers at risk are more likely to be regular smokers, start smoking at a younger age, and smoke with greater intensity (Weinberger et al., 2015a); these findings are in line with the findings from a study among Spanish students (Míguez \& Becona, 2015). These results are consistent with recognized theories of adolescent substance use such as Jessor's problem-behavior theory (Donovan, Jessor, \& Costa, 1991; Jessor, 1991) or general deviance syndrome theory (McGee \& Newcomb, 1992), claiming that various forms of risk behavior and attitudes coexist among adolescents.

Although the existing evidence clearly shows a positive relationship between problem gambling and smoking in adolescence, to date, very little is known about causality and severity interactions. This study aims to analyze the relationship between smoking and gambling among Czech adolescents, with a focus on the relation between the intensity of smoking, early initiation into smoking, and the intensity of gambling and the risk of the development of problem gambling.

\section{DATA AND METHODS}

\section{Sample}

Data were collected as part of the European School Survey Project on Alcohol and Other Drugs (ESPAD) 2015, a cross-sectional questionnaire survey focusing on substance use among 15- to 16-year-old students that was carried out in 35 European countries (Chomynová et al., 2016; The ESPAD Group, 2016).

The ESPAD target population is defined as regular students who turn 16 years in the calendar year of the data collection (students born in 1999 for the 2015 survey), who are present in the classroom on the day of the survey (Hibell, 2014). The ESPAD study covers all grades containing at least $10 \%$ of the target population (i.e., the ninth grade of middle schools, first grade of secondary schools, and relevant grades of 8-year grammar schools). A stratified random sample of schools from all regions of the Czech Republic was prepared to ensure a representative sample of schools according to the region and type of school. The participation of the students was voluntary; students had the right to refuse to fill in the questionnaire; altogether eight students refused to participate. The average time needed to complete the questionnaire was $46 \mathrm{~min}$; younger students in middle schools needed more time compared to grammar school students. The Czech version of the ESPAD questionnaire was pilot-tested in one selected school prior to the survey data collection.

In the Czech Republic, a total of 6,707 self-completed questionnaires were collected at 209 randomly selected middle and secondary schools of all types in all regions of the country. For the purpose of the international ESPAD comparisons, only nationally representative samples of students reaching 16 years in the year of data collection are used $(N=2,738$ in the Czech Republic in 2015); for the purpose of our analysis, we included all 6,082 valid observations from all students aged 15-19 years present in selected classes on the date of the data collection $(50.1 \%$ boys and $49.9 \%$ girls). The aim of our analysis was to investigate risk factors related to problem gambling among Czech adolescents. Enlarging the data set to more than double significantly improves the precision of the results, especially when the subpopulation at risk is relatively small, and it allows the effect of age to be inspected, which would not be possible only among the subpopulation of 15- to 16-year-olds.

\section{Measures}

Logistic regression was used to identify the risk factors of problem gambling. The following independent variables entered the analysis: age, gender, school type, family structure (both parents $=1$ /different family structure $=0$ ), three smoking status variables (occasional smoker $=1$ / other $=0$; moderate daily smoker smoking up to 10 cigarettes a day $=1 /$ other $=0$; heavy daily smoker smoking $11+$ cigarettes a day $=1 /$ other $=0$ ), and two variables of early initiation of daily smoking (at the age of 12 or earlier $=1$ / other $=0$; at the age of 13 or $14=1 /$ other $=0$ ). The dependent variable of problem gambling was based on the Lie/Bet scale (Johnson et al., 1997) consisting of two items: "Have you ever had to lie to people important to you about how much you gambled?" (yes = $1 /$ no =0) and "Have you ever felt the need to bet more and more money?" (yes = 1/no = 0); students scoring 0 points for both questions were considered non-risky (0), whereas students scoring 1 or 2 points were considered to be at-risk gamblers (1).

A linear regression model was carried out on the subsample of students at risk according to the Lie/Bet scale in order to inspect the effect of the intensity of smoking on the intensity of gambling. The Consumption Screen for Problem Gambling (CSPG; Rockloff, 2012) was used to measure the intensity of gambling. The CSPG score entered the model as a dependent variable with the same explanatory variables as presented in the previous model. The CSPG consists of three questions measuring: (a) gambling frequency: "How often (if ever) have you gambled money in the last 12 months?" reported on a scale "I have not gambled money" $=0$, "monthly or less" $=1$, , $2-4$ times a month" $=2$, "2-3 times a week" = 3, "4-5 times a week" =4, and "6 or more times a week" $=5$; (b) time spent on gambling: "How much time did you spend gambling on a typical day in 
which you gambled in the last 12 months?" reported on a scale "I have not gambled money" $=0$ and "less than $30 \mathrm{~min} "=0$, "between $30 \mathrm{~min}$ and $1 \mathrm{hr}$ " $=1$, "between 1 and $2 \mathrm{hr}$ " $=2$, "between 2 and $3 \mathrm{hr}$ " $=3$, and " $3 \mathrm{hr}$ or more" = 4; and (c) gambling intensity: "How often did you spend more than $2 \mathrm{hr}$ gambling (on a single occasion) in the last 12 months?" reported on a scale "I have not gambled money" $=0$ and "never" $=0$, "less than monthly" $=1$, "monthly" $=2$, "weekly" $=3$, and "daily or almost daily" $=4$. Summing up the scores on the three questions, the respondents can gain $0-13$ points on the scale; respondents scoring $0-1$ points were considered at no risk, those with a sum of 2-3 points were considered at low risk, and those scoring $4+$ points were considered at high risk of problem gambling. The cut-off points were calculated according to the literature to provide results comparable to those of other surveys and/or countries (Rockloff, 2012). For the purposes of this paper, the terms "gamblers at risk of problem gambling" and "problem gamblers" are used interchangeable.

\section{Hypotheses}

A model was conducted to test for the following hypotheses:

1. Smoking status is a risk factor for the development of problem gambling.

2. The relationship between smoking and gambling is more pronounced when intensity is taken into account.

3. The age of smoking initiation plays a significant role in the development of problem gambling than smoking status itself.

\section{Missing values}

The majority of the students $(78 \%)$ left some answers in the questionnaire blank. On average, three answers were missing per completed questionnaire. Only 124 students $(2 \%)$ did not answer one or more questions analyzed in the models. These missing values were treated as non-risky behavior for the analysis as students reporting no risk behavior in a given time frame skipped questions asking about the frequency or intensity of such behavior in more detail. The elimination of these observations did not lead to statistically different coefficients in the model.

\section{Ethics}

The ESPAD study is a cross-sectional questionnaire survey carried out in randomly selected schools; the emphasis is placed on anonymity and voluntary participation. No ethical committee approval was required for the ESPAD study in the Czech Republic in 2015, as it was already the sixth wave of data collection within this international project. As the participating respondents were aged over 15 years, no parental consent for the students' participation was required. The researchers followed all relevant legislation in the Czech Republic with regard to personal data protection, that is, no personal data identifying individual students were requested. The participants returned their questionnaires in sealed envelopes in order to protect their anonymity, and the mass processing of the data guaranteed their anonymity.

\section{RESULTS}

Prevalence of problem gambling among Czech adolescents

The proportion of students at risk of problem gambling on the basis of the Lie/Bet scale was nearly $8 \%$. A higher proportion of students at risk of problem gambling were observed among secondary school students (8\%) compared to middle school students $(5 \%)$. The significant difference between male and female students (13\% of the males at risk, compared to $2 \%$ of the females) is in line with findings observed in previous studies on adolescent gambling.

Only a slight difference between occasional and moderate daily smokers and current non-smokers in terms of the prevalence of problem gambling was observed (Table 1). A significantly higher prevalence of problem gambling was found among heavy smokers, who showed a prevalence rate double that of non-smokers.

As regards, the age at which the first cigarette was smoked, the highest prevalence of problem gambling was observed among the youngest smokers (starting at the age of nine or younger), while starting smoking at 13 years or older did not increase the risk of problem gambling as compared with non-smokers.

The age of initiation into daily smoking seems to be a more reliable marker of the risk of problem gambling than smoking status or the age at which the first cigarette was smoked. One fifth of the students who smoked daily at the age of 12 or earlier were at risk of problem gambling. With postponement of the initiation into daily smoking to 13 or 14 years, the prevalence rate decreased sharply to $10 \%$, and further to $7 \%$ among those who started smoking daily at 15 years or later.

When the population of daily smokers is sorted according to the age at which they initiated with smoking, a clear positive relationship can be observed between the risk of problem gambling and the age of daily smoking initiation (Figure 1).

The increased prevalence of problem gambling among early smokers may also be explained by the fact that early smokers are often heavy smokers, leading to a correlation between heavy smoking and problem gambling. However, when the age of initiation of daily smoking was controlled for by excluding students who started to smoke daily before the age of 15 years, no significant differences were observed between different levels of intensity of smoking. This suggests that it is the early initiation of daily smoking rather than intensity of smoking that increases the risk of problem gambling (Figure 2).

\section{Problem gambling intensity and smoking intensity}

The relationship between the intensity of gambling and smoking among the subgroup of adolescent gamblers at risk of problem gambling was further analyzed using the CSPG.

When the means of the CSPG score between smoking and non-smoking gamblers at risk were compared, a significantly higher score was observed among smoking gamblers (Figure 3). According to the CSPG, non-smoking individuals gamble with lower intensity and face a lower risk of problem gambling than their smoking peers. 
Problem gambling and tobacco smoking among Czech adolescents

Table 1. Prevalence of problem gambling among Czech adolescents

\begin{tabular}{|c|c|c|c|c|c|c|}
\hline & \multicolumn{3}{|c|}{ Lie/Bet score (distribution in \%) } & \multirow{2}{*}{$\begin{array}{l}\text { At risk ( } 1 \text { or } 2 \text { points } \\
\text { in } \% \text { Lie/Bet })\end{array}$} & \multirow[b]{2}{*}[95\%\mathrm{CI}]{} & \multirow[b]{2}{*}{ Total $(N)$} \\
\hline & 0 & 1 & 2 & & & \\
\hline Total & 92.34 & 6.68 & 0.99 & 7.66 & {$[7.0-8.3]$} & 6,082 \\
\hline \multicolumn{7}{|l|}{ Gender } \\
\hline Male & 87.07 & 11.32 & 1.61 & 12.93 & {$[11.7-14.1]$} & 3,047 \\
\hline Female & 97.63 & 2.01 & 0.36 & 2.37 & {$[1.8-2.9]$} & 3,035 \\
\hline \multicolumn{7}{|l|}{ Type of school } \\
\hline Middle & 95.01 & 4.12 & 0.87 & 4.99 & {$[7.6-9.1]$} & 1,263 \\
\hline Secondary & 91.64 & 7.35 & 1.02 & 8.36 & {$[3.8-6.2]$} & 4,819 \\
\hline \multicolumn{7}{|l|}{ Current smoking status } \\
\hline Non-smoker & 92.86 & 6.45 & 0.69 & 7.14 & {$[6.4-7.9]$} & 4,187 \\
\hline Occasional smoker & 91.76 & 7.17 & 1.08 & 8.24 & {$[6.4-10.1]$} & 837 \\
\hline Moderate daily smoker & 92.65 & 6.02 & 1.34 & 7.35 & {$[5.5-9.2]$} & 748 \\
\hline Heavy daily smoker & 86.13 & 10.00 & 3.87 & 13.87 & {$[10.0-17.7]$} & 310 \\
\hline \multicolumn{7}{|l|}{ First cigarette } \\
\hline Never & 93.25 & 6.25 & 0.50 & 6.75 & {$[5.7-7.8]$} & 2,016 \\
\hline At 9 years or earlier & 87.13 & 9.65 & 3.22 & 12.87 & {$[9.6-16.1]$} & 404 \\
\hline At $10-12$ years & 90.57 & 7.70 & 1.73 & 9.43 & {$[7.8-11.0]$} & 1,273 \\
\hline At 13 or 14 years & 93.07 & 6.35 & 0.58 & 6.93 & {$[5.7-8.2]$} & 1,544 \\
\hline At 15 years or later & 93.96 & 5.33 & 0.71 & 6.04 & {$[4.4-7.6]$} & 845 \\
\hline \multicolumn{7}{|l|}{ Initiation of daily smoking } \\
\hline Never & 92.88 & 6.37 & 0.76 & 7.12 & {$[6.4-7.9]$} & 4,492 \\
\hline At 9 years or earlier & 65.22 & 26.09 & 8.70 & 34.78 & {$[15.3-54.2]$} & 23 \\
\hline At $10-12$ years & 81.88 & 12.75 & 5.37 & 18.12 & [11.9-24.3] & 149 \\
\hline At 13 or 14 years & 90.00 & 8.49 & 1.51 & 10.00 & {$[7.4-12.6]$} & 530 \\
\hline At 15 years or later & 93.47 & 5.63 & 0.90 & 6.53 & {$[4.9-8.2]$} & 888 \\
\hline
\end{tabular}

Note. CI: confidence interval.

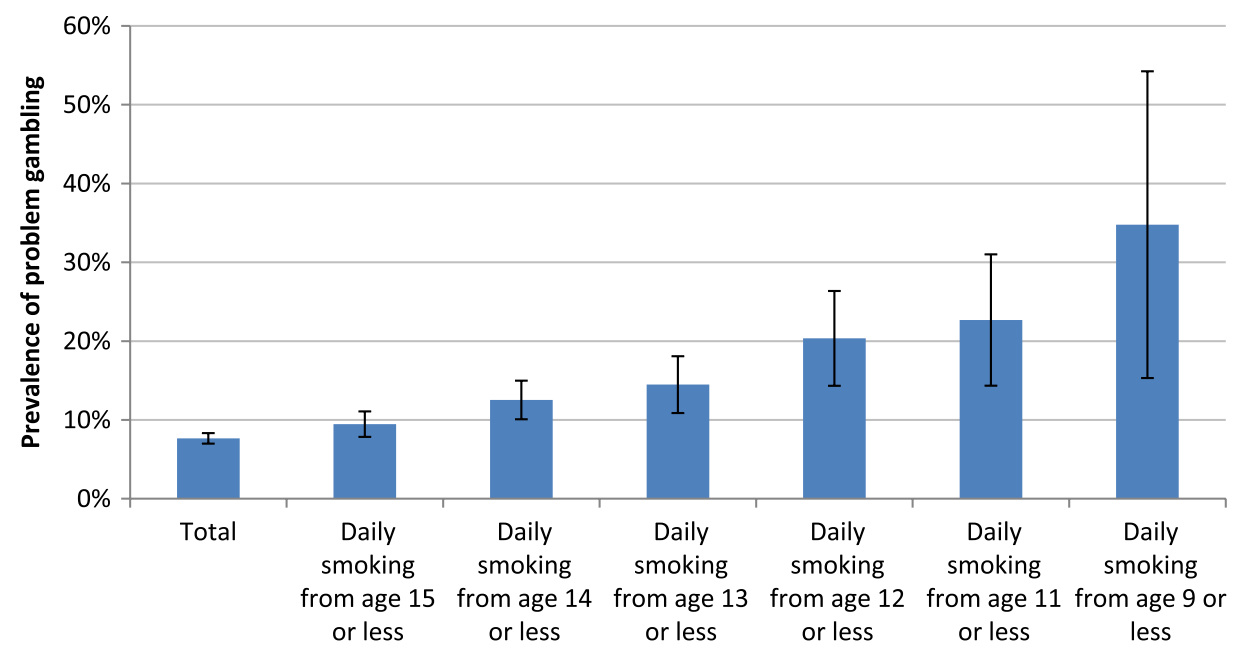

Figure 1. Prevalence of problem gambling by initiation into daily smoking. Note. The black lines represent $95 \%$ confidence intervals

Gamblers who smoke up to 10 cigarettes a day, or smoke occasionally, achieve similar CSPG scores (around 3 points) and do not differ significantly from non-smokers. A significantly higher intensity of gambling is associated with heavy smoking $(11+$ cigarettes a day). On average, heavy smokers scored 5+ points on the CSPG scale, which suggests a high intensity of gambling with a high risk of developing problem gambling.

The hypothesis that early initiation into daily smoking increases the risk of problem gambling was further tested in a logistic regression model. In line with the hypothesis, smokers who start smoking daily at an early age should be at higher risk of problem gambling even when other explanatory variables such as gender, age, the type of the school (middle or secondary school), or family composition are controlled for. The logistic regression model showed that the variables of early initiation into daily smoking are significant - students who started smoking daily at the age of 12 years or earlier have 2.7 times higher odds of problem gambling than smokers who started later or non-smokers. 


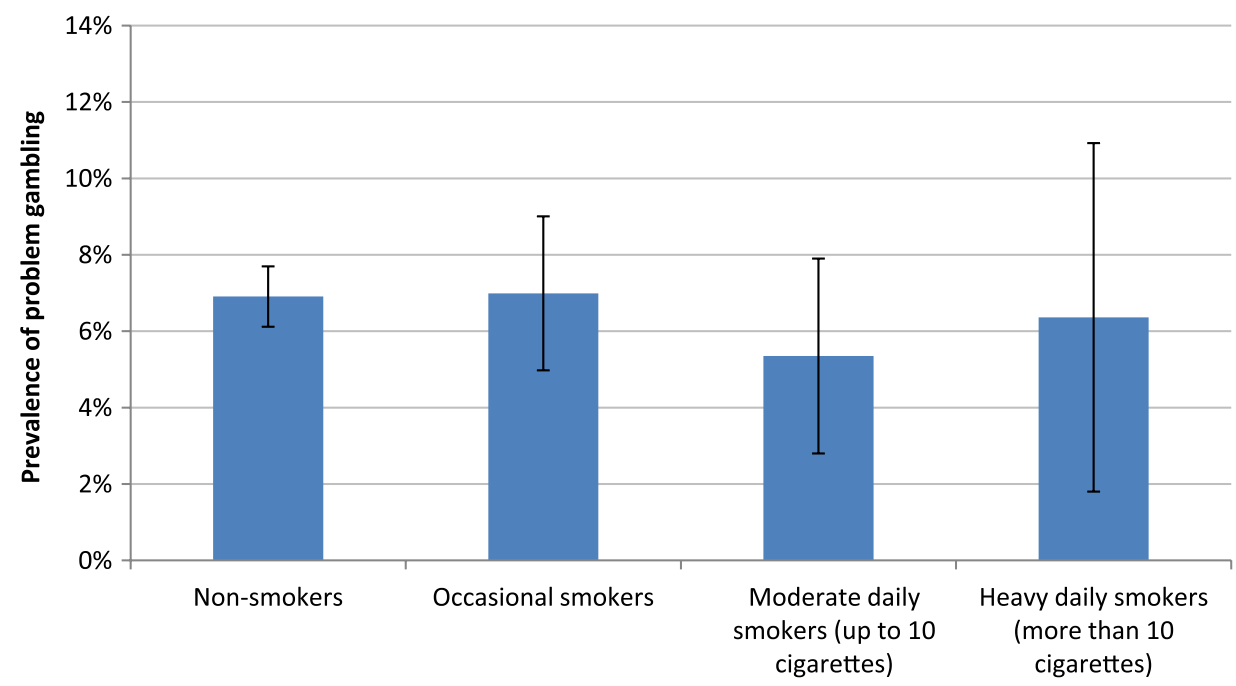

Figure 2. Prevalence of problem gambling in a subsample excluding daily smokers starting before the age of 15 years. Note. The black lines represent $95 \%$ confidence intervals

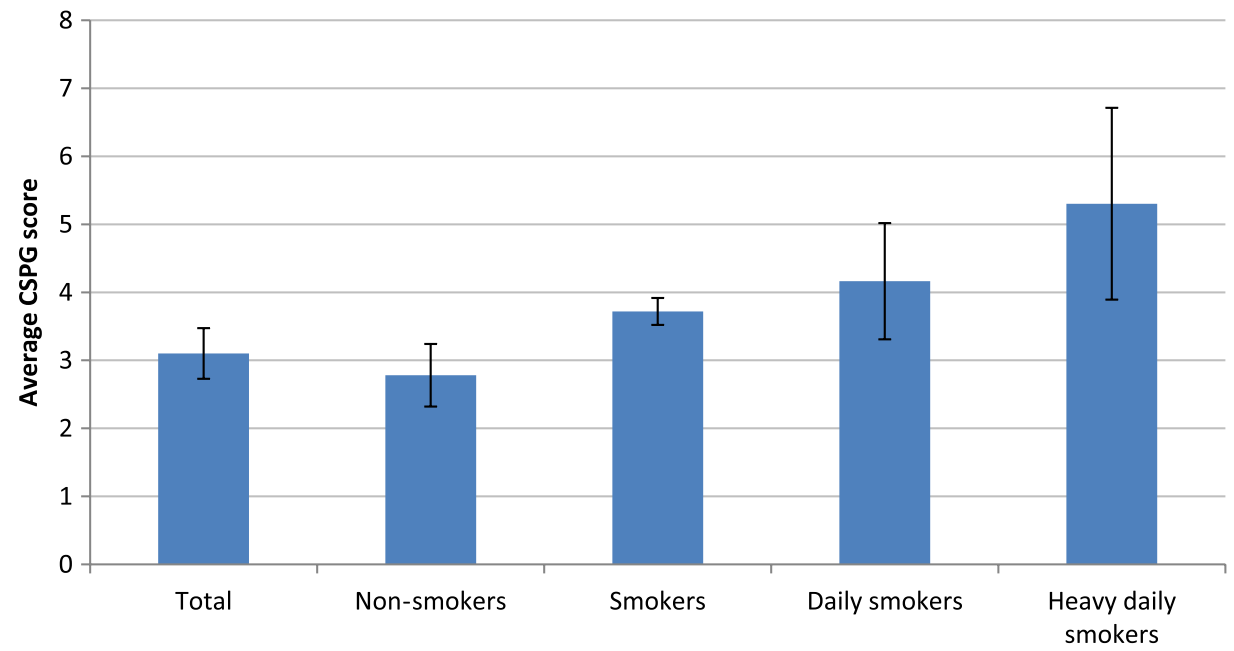

Figure 3. Smoking status and average CSPG score of gamblers at risk. Note. The black lines represent $95 \%$ confidence intervals

Those who start smoking at the age of 13 or 14 years have odds ratios (ORs) around 1.6. As already suggested, the variables of the intensity of smoking are not significant (OR close to 1). As expected, being male especially, older, and a student of a secondary school (rather than middle school) increases the chances of being a problem gambler, while a complete family composition acts as a protective factor (Table 2).

In addition, gamblers at risk of problem gambling were inspected in order to show how the intensity of smoking affects the intensity of gambling. To understand which of the two factors - the intensity of smoking or early initiation into daily smoking - predicts a higher CSPG score, a linear regression model with the logarithm of the CSPG score as a dependent variable was created, using the same explanatory variables as in the previous model (Table 3). On average, male gamblers scored about $60 \%$ higher than their female peers. In line with previous analysis, heavy smoking increases the CSPG score by $75 \%$. The age of initiation into daily smoking is an important factor for the intensity of gambling - gamblers smoking daily at the age of 12 years or earlier scored $84 \%$ higher.

\section{DISCUSSION}

This study represents the first attempt to investigate the relationship between problem gambling and smoking among adolescents in the Czech Republic. Using the ESPAD data, we presented the relationship between problem gambling and smoking, which shows that early initiation into daily smoking increases the risk of problem gambling as well as the intensity of gambling in problem gamblers. Interestingly, and contradictory to Weinberger et al. (2015a), no clear evidence for an association between the intensity of smoking and the risk of problem gambling was shown. On the other hand, among gamblers who are already at risk, a high intensity of smoking is associated with a higher intensity of gambling. 
Table 2. Predictors of problem gambling - Logistic regression

\begin{tabular}{|c|c|c|c|c|c|}
\hline & $B$ & $S E$ & $z$ statistics & $p$ & Odds ratio $[95 \% \mathrm{CI}]$ \\
\hline Intercept & -6.587 & 1.174 & -5.613 & .000 & - \\
\hline Male & 1.774 & 0.132 & 13.451 & .000 & $5.9[4.6-7.7]$ \\
\hline Age & 0.181 & 0.070 & 2.589 & .010 & $1.2[1.0-1.4]$ \\
\hline Middle school & -0.345 & 0.162 & -2.135 & .033 & $0.7[0.5-1.0]$ \\
\hline Daily smoker from 13 or 14 years & 0.449 & 0.178 & 2.529 & .011 & $1.6[1.1-2.2]$ \\
\hline Daily smoker at the age of 12 years or earlier & 1.000 & 0.214 & 4.679 & .000 & $2.7[1.8-4.1]$ \\
\hline Living with both parents & -0.221 & 0.102 & -2.165 & .030 & $0.8[0.7-1.0]$ \\
\hline Occasional smoker & 0.122 & 0.146 & 0.836 & .403 & $1.1[0.8-1.5]$ \\
\hline Daily smoker - up to 10 cigarettes a day & -0.235 & 0.170 & -1.379 & .168 & $0.8[0.6-1.1]$ \\
\hline Daily smoker - more than 10 cigarettes a day & 0.263 & 0.199 & 1.321 & .187 & $1.3[0.9-1.9]$ \\
\hline
\end{tabular}

Note. Model: Observations $=6,082$; Akaike information criterion $=2,981$; Nagelkerke's $R^{2}=.126 ; S E$ : standard error; CI: confidence interval.

Table 3. Predictors of CSPG score - Linear regression on a subsample of gamblers in risk

\begin{tabular}{lrrrcc}
\hline & $B$ & $S E$ & $t$ statistics & $p$ & $\%$ change [95\% CI] \\
\hline Intercept & -0.839 & 1.030 & -0.815 & .416 & $-83.9[-289.8-122.0]$ \\
Male & 0.474 & 0.123 & 3.868 & .000 & $60.7[25.7-105.3]$ \\
Age & 0.071 & 0.063 & 1.136 & .257 & $7.1[-5.4-19.6]$ \\
Middle school & 0.026 & 0.166 & 0.155 & .877 & $2.6[-26.4-43.0]$ \\
Daily smoker from 13 or 14 years & 0.149 & 0.173 & 0.858 & .391 & $16.0[-17.9-64.1]$ \\
Daily smoker at the age of 12 years or earlier & 0.610 & 0.205 & 2.968 & .003 & $84.0[22.0-177.5]$ \\
Living with both parents & -0.046 & 0.102 & -0.453 & .651 & $-4.5[-22.0-17.0]$ \\
Occasional smoker & 0.121 & 0.145 & 0.832 & .406 & $12.8[-15.6-50.8]$ \\
Daily smoker - up to 10 cigarettes a day & 0.087 & 0.162 & 0.540 & .590 & $9.1[-21.0-50.7]$ \\
Daily smoker - more than 10 cigarettes a day & 0.559 & 0.217 & 2.582 & .010 & $75.0[13.4-169.9]$ \\
\hline
\end{tabular}

Note. Model: Observations $=466 ; R^{2}=.087$; Adjusted $R^{2}=.069$; CSPG: Consumption Screen for Problem Gambling; SE: standard error; CI: confidence interval.

Slutske, Moffitt, Poulton, and Caspi (2012) argued that the individual risk of being addicted to pathological behavior depends strongly on the individual's temperament, which is observable as soon as at the age of 3 years; and both impulsivity and sensation-seeking play an important role in the development of risk behaviors such as substance use and gambling. Working on the presumption, it means that students with low behavioral and emotional self-control (e.g., with increased impulsivity) tend to engage in risky behavior, such as daily smoking, binge drinking, use of other substances, or gambling. Since cigarettes are one of the most accessible addictive substances in the Czech environment, early initiation into daily smoking may represent an important indicator for general vulnerability for the development of risky behavior, including problem gambling. However, as some authors (Canale, Scacchi, \& Griffiths, 2016; Leeman, Hoff, Krishnan-Sarin, PatockPeckham, \& Potenza, 2014; Malmberg et al., 2013) have argued, part of the relationship between impulsivity, sensation-seeking, and participation in gambling might be influenced by involvement in a part-time job that provided adolescents with money available for gambling activities.

Adolescent problem gambling is strongly associated with impulsivity and delay discounting (Cosenza \& Nigro, 2015; Nigro \& Cosenza, 2016), and the same cognitive distortions are also connected to smoking (Friedel, Dehart, Madden, \& Odum, 2014). Individuals with impulsivity and steep delay discounting may be regarded as a vulnerable group suitable for prevention and intervention programs targeted at all kinds of risk behaviors, focusing on the most prevalent risk activities. In general, adolescents "living in the now" (Nigro \& Cosenza, 2016) might be at greater risk of any problem behavior. Our finding that earlier initiation into smoking is associated with the development of problem gambling some years later might also be explained by the common risk factor of impulsivity and delay discounting.

Empirical evidence also shows that gambling in adolescence is associated not only with the use of tobacco, but also with other substances such as alcohol, illicit drugs (especially cannabis, but also cocaine or non-medical use of prescription drugs), or energy drinks (Canale et al., 2017; Cook et al., 2015; Vieno et al., 2018). It is also associated with risky sexual behavior (Martins, Lee, Kim, Letourneau, \& Storr, 2014; Räsänen, Lintonen, Joronen, \& Konu, 2015) and other health risks and various forms of anti-social behavior such as driving under the influence of alcohol, being involved in a fight, or carrying a weapon (Chaumeton, Ramowski, \& Nystrom, 2011; Mishra, Lalumière, Morgan, \& Williams, 2011; Proimos, DuRant, Pierce, \& Goodman, 1998).

In this study, adolescents already at risk of problem gambling gambled more intensively if they had started smoking at the age of 12 years or earlier and/or if they smoked 11 or more cigarettes a day. Even when heavy smoking itself does not significantly increase the risk of 
problem gambling as measured by the Lie/Bet screen, it predicts a higher intensity of gambling in gamblers at risk. Such results argue in favor of the problem behavior theory (Jessor, 1991) suggesting that impulsivity increases the risk of smoking and gambling addiction and that impulsive behavior leads to more intensive smoking and gambling. At the moment, we are not aware of any comparable study in another country that may confirm or refute these findings. However, we believe that our findings may be generalized to other (European) countries, as they try to describe a general relationship between two different forms of risk behavior among adolescents. More research is needed to understand the multifaceted association between smoking and gambling as they coexist in adolescence, being also associated with other forms of risk behaviors from very early ages.

These findings may have implications for prevention policy. In this study, early initiation into daily smoking in late childhood has proved to be a strong predictor of problem gambling in adolescence. Early interventions targeted at young smokers should aim not only at their quitting smoking but also at preventing smokers from developing the risk of problem gambling and other risk behaviors.

\section{Limitations of this study}

Several limitations of this study exist. The ESPAD study's target population is the cohort of 15- to 16-year-old students attending regular schools that are randomly selected in order to reach a representative sample on a national level. In order to investigate risk factors related to problem gambling among Czech students, we decided, for the purpose of our analysis, to include all valid observations collected within the project. Similarly to other cross-sectional surveys, the ESPAD data do not allow testing for the causality of the relationship between different forms of risky behaviors, so including students of other ages may help to shed light on the associations between the variables analyzed. Another limitation of the study lies in the self-reporting design of the ESPAD questionnaire; students might overestimate, as well as underestimate, their responses. Moreover, school surveys like ESPAD use cluster sampling, which would increase the size of the confidence intervals. Still, the ESPAD study is considered to be a valuable source of data on adolescent risky behavior (e.g., Király et al., 2014; Molinaro et al., 2014; Vorobjov, Saat, \& Kull, 2014), including participation in gambling activities (Molinaro et al., 2018).

\section{CONCLUSIONS}

Early initiation of daily smoking increases the risk of problem gambling and the intensity of gambling in problem gamblers. However, the relationship between adolescent smoking and gambling seems to be more complex than just simply positively correlated. On the basis of the results of this study, it is highly probable that the relationship is rather indirect. Early daily smoking, as well as other substance use and problem gambling, is likely to arise from common psychological traits expressed as impulsive behavior.
The identification of pre-adolescent daily smokers and prevention programs targeting those not only at risk of smoking, but also of other forms of substance use and risk behavior, including excessive gambling, could significantly reduce the prevalence of adverse consequences in adolescents and help them to pass through adolescence in a better health and social state.

Funding sources: This paper was supported by the project No. LO1611 with a financial support from the Ministry of Education, Youth, and Sports of the Czech Republic under the NPU I program.

Authors' contribution: PCh and VM were responsible for the survey data collection and ESPAD survey methodology compliance. MŠ drafted the paper and performed statistical analyses. All authors contributed to literature review and the final revision of the manuscript. All authors had full access to the survey data and read and approved the final manuscript.

Conflict of interest: The authors declare no conflict of interest.

\section{REFERENCES}

Calado, F., Alexandre, J., \& Griffiths, M. D. (2017). Prevalence of adolescent problem gambling: A systematic review of recent research. Journal of Gambling Studies, 33(2), 397-424. doi:10.1007/s10899-016-9627-5

Canale, N., Scacchi, L., \& Griffiths, M. D. (2016). Adolescent gambling and impulsivity: Does employment during high school moderate the association? Addictive Behaviors, 60, 37-41. doi:10.1016/j.addbeh.2016.04.001

Canale, N., Vieno, A., Billieux, J., Lazzeri, G., Lemma, P., \& Santinello, M. (2017). Is medicine use for nervousness associated with adolescent at-risk or problem gambling? European Addiction Research, 23(4), 171-176. doi:10.1159/000479001

Chaumeton, N. R., Ramowski, S. K., \& Nystrom, R. J. (2011). Correlates of gambling among eighth-grade boys and girls. Journal of School Health, 81(7), 374-385. doi:10.1111/j.17461561.2011.00605.x

Chomynová, P., Csémy, L., \& Mravčík, V. (2016). Evropská školní studie o alkoholu a jiných drogách (ESPAD) 2015 [The European School Survey Project on Alcohol and Other Drugs (ESPAD) 2015]. Zaostřeno, 14(5), 1-16. Retrieved from https://www.drogy-info.cz/data/obj_files/32196/734/zaostreno_ 2016-05_v03.pdf

Cook, S., Turner, N. E., Ballon, B., Paglia-Boak, A., Murray, R., Adlaf, E. M., Ilie, G., den Dunnen, W., \& Mann, R. E. (2015). Problem gambling among Ontario students: Associations with substance abuse, mental health problems, suicide attempts, and delinquent behaviours. Journal of Gambling Studies, 31(4), 1121-1134. doi:10.1007/s10899-014-9483-0

Cosenza, M., \& Nigro, G. (2015). Wagering the future: Cognitive distortions, impulsivity, delay discounting, and time 
perspective in adolescent gambling. Journal of Adolescence, 45, 56-66. doi:10.1016/j.adolescence.2015.08.015

Delfabbro, P., King, D. L., \& Derevensky, J. L. (2016). Adolescent gambling and problem gambling: Prevalence, current issues, and concerns. Current Addiction Reports, 3(3), 268-274. doi:10.1007/s40429-016-0105-z

Derevensky, J. L., Gupta, R., \& Winters, K. (2003). Prevalence rates of youth gambling problems: Are the current rates inflated? Journal of Gambling Studies, 19(4), 405-425. doi:10.1023/A:1026379910094

Donovan, J. E., Jessor, R., \& Costa, F. M. (1991). Adolescent health behavior and conventionality-unconventionality: An extension of problem-behavior theory. Health Psychology, 10(1), 52-61. doi:10.1037/0278-6133.10.1.52

Friedel, J. E., Dehart, W. B., Madden, G. J., \& Odum, A. L. (2014). Impulsivity and cigarette smoking: Discounting of monetary and consumable outcomes in current and non-smokers. Psychopharmacology, 231(23), 4517-4526. doi:10.1007/ s00213-014-3597-z

Hayatbakhsh, M. R., Clavarino, A., Williams, G. M., Bor, W., \& Najman, J. M. (2012). Young adults' gambling and its association with mental health and substance use problems. Australian and New Zealand Journal of Public Health, 36(2), 160-166. doi:10.1111/j.1753-6405.2011.00815.x

Hibell, B. (2014). Overview of the ESPAD Project: Background, methodology and organisation. The ESPAD Handbook, Section 2. Lisbon, Portugal: EMCDDA.

Jessor, R. (1991). Risk behavior in adolescence: A psychological framework for understanding and action. Journal of Adolescent Health, 12(8), 597-605. doi:10.1016/1054-139X(91) 90007-K

Johnson, E. E., Hamer, R., Nora, R. M., Tan, B., Eisenstein, N., \& Engelhart, C. (1997). The Lie/Bet Questionnaire for screening pathological gamblers. Psychological Reports, 80, 83-88. doi:10.2466/pr0.1997.80.1.83

Király, O., Griffiths, M. D., Urbán, R., Farkas, J., Kökönyei, G., Elekes, Z., Tamás, D., \& Demetrovics, Z. (2014). Problematic Internet use and problematic online gaming are not the same: Findings from a large nationally representative adolescent sample. Cyberpsychology, Behavior, and Social Networking, 17(12), 749-754. doi:10.1089/cyber.2014.0475

Kong, G., Tsai, E., Pilver, C. E., Tan, H. S., Hoff, R. A., Cavallo, D. A., Krishnan-Sarin, S., Steinberg, M. A., Rugle, L., \& Potenza, M. N. (2013). Differences in gambling problem severity and gambling and health/functioning characteristics among Asian-American and Caucasian high-school students. Psychiatry Research, 210(3), 1071-1078. doi:10.1016/ j.psychres.2013.10.005

Leeman, R. F., Hoff, R. A., Krishnan-Sarin, S., Patock-Peckham, J. A., \& Potenza, M. N. (2014). Impulsivity, sensation-seeking, and part-time job status in relation to substance use and gambling in adolescents. Journal of Adolescent Health, 54(4), 460-466. doi:10.1016/j.jadohealth.2013.09.014

Malmberg, M., Kleinjan, M., Overbeek, G., Vermulst, A. A., Lammers, J., \& Engels, R. C. (2013). Are there reciprocal relationships between substance use risk personality profiles and alcohol or tobacco use in early adolescence? Addictive Behaviors, 38(12), 2851-2859. doi:10.1016/j. addbeh.2013.08.003

Martins, S. S., Lee, G. P., Kim, J. H., Letourneau, E. J., \& Storr, C. L. (2014). Gambling and sexual behaviors in
African-American adolescents. Addictive Behaviors, 39(5), 854-860. doi:10.1016/j.addbeh.2014.02.002

McGee, L., \& Newcomb, M. D. (1992). General deviance syndrome: Expanded hierarchical evaluations at four ages from early adolescence to adulthood. Journal of Consulting and Clinical Psychology, 60(5), 766-776. doi:10.1037/0022006X.60.5.766

Míguez, M. C., \& Becona, E. (2015). Do cigarette smoking and alcohol consumption associate with cannabis use and problem gambling among Spanish adolescents? Addiciones, 27(1), 8-16. doi:10.20882/adicciones.189

Mishra, S., Lalumière, M. L., Morgan, M., \& Williams, R. J. (2011). An examination of the relationship between gambling and antisocial behavior. Journal of Gambling Studies, 27(3), 409-426. doi:10.1007/s10899-010-9217-x

Molinaro, S., Benedetti, E., Scalese, M., Bastiani, L., Fortunato, L., Cerrai, S., Canale, N., Chomynova, P., Elekes, Z., Feijão, F., Fotiou, A., Kokkevi, A., Kraus, L., Rupšien , L., Monshouwer, K., Nociar, A., Strizek, J., \& Urdih Lazar, T. (2018). Prevalence of youth gambling and potential influence of substance use and other risk factors throughout 33 European countries: First results from the 2015 ESPAD study. Addiction, 113(10), 1862-1873. doi:10.1111/add.14275

Molinaro, S., Canale, N., Vieno, A., Lenzi, M., Siciliano, V., Gori, M., \& Santinello, M. (2014). Country- and individual-level determinants of probable problematic gambling in adolescence: A multi-level cross-national comparison. Addiction, 109(12), 2089-2097. doi:10.1111/add.12719

Nigro, G., \& Cosenza, M. (2016). Living in the now: Decisionmaking and delay discounting in adolescent gamblers. Journal of Gambling Studies, 32(4), 1191-1202. doi:10.1007/s10899016-9595-9

Proimos, J., DuRant, R. H., Pierce, J. D., \& Goodman, E. (1998). Gambling and other risk behaviors among 8th- to 12th-grade students. Pediatrics, 102(2), e23. doi:10.1542/ peds.102.2.e23

Räsänen, T., Lintonen, T., Joronen, K., \& Konu, A. (2015). Girls and boys gambling with health and well-being in Finland. Journal of School Health, 85(4), 214-222. doi:10.1111/ josh.12246

Richard, D. C. S., Blaszczynski, A., \& Nower, L. (2014). The Wiley-Blackwell handbook of disordered gambling. Chichester, UK: John Wiley \& Sons, Ltd.

Rockloff, M. J. (2012). Validation of the Consumption Screen for Problem Gambling (CSPG). Journal of Gambling Studies, 28(2), 207-216. doi:10.1007/s10899-011-9260-2

Slutske, W. S., Moffitt, T. E., Poulton, R., \& Caspi, A. (2012). Undercontrolled temperament at age 3 predicts disordered gambling at age 32: A longitudinal study of a complete birth cohort. Psychological Science, 23(5), 510-516. doi:10.1177/ 0956797611429708

The ESPAD Group. (2016). ESPAD report 2015. Results from the European School Survey Project on Alcohol and Other Drugs (p. 99). Luxembourg: Publications Office of the European Union.

United States Department of Health and Human Services. (2014). The health consequences of smoking - 50 years of progress. A report of the Surgeon General. Rockville, MD: United States Department of Health and Human Services.

Vieno, A., Canale, N., Potente, R., Scalese, M., Griffiths, M. D., \& Molinaro, S. (2018). The multiplicative effect of 
combining alcohol with energy drinks on adolescent gambling. Addictive Behaviors, 82, 7-13. doi:10.1016/j. addbeh.2018.01.034

Volberg, R. A., Gupta, R., Griffiths, M. D., Olason, D. T., \& Delfabbro, P. (2010). An international perspective on youth gambling prevalence studies. International Journal of Adolescent Medicine and Health, 22(1), 3-38. doi:10.1515/ IJAMH.2010.22.1.3

Vorobjov, S., Saat, H., \& Kull, M. (2014). Social skills and their relationship to drug use among 15-16-year-old students in Estonia: An analysis based on the ESPAD data. Nordic Studies on Alcohol and Drugs, 31(4), 401-412. doi:10.2478/nsad2014-0031
Weinberger, A. H., Franco, C. A., Hoff, R. A., Pilver, C., Steinberg, M. A., Rugle, L., Wampler, J., Cavallo, D. A., Krishnan-Sarin, S., \& Potenza, M. N. (2015a). Cigarette smoking, problem-gambling severity, and health behaviors in high-school students. Addictive Behaviors Reports, 1, 40-48. doi:10.1016/j.abrep.2015.01.001

Weinberger, A. H., Franco, C. A., Hoff, R. A., Pilver, C. E., Steinberg, M. A., Rugle, L., Wampler, J., Cavallo, D. A., Krishnan-Sarin, S., \& Potenza, M. N. (2015b). Gambling behaviors and attitudes in adolescent high-school students: Relationships with problem-gambling severity and smoking status. Journal of Psychiatric Research, 65, 131-138. doi:10.1016/j.jpsychires.2015.04.006 